\title{
DOCENTE-FORMADORA-PESQUISADORA EM DEVIR: REFLETINDO SOBRE O ESTÁGIO MEDIADO POR EIXOS INTEGRADORES
}

\author{
TEACHER-TRAINER-RESEARCHER UNDER CONSTRUCTION: REFLECTING ON TEACHING \\ INTERNSHIP MEDIATED BY INTEGRATING AXES
}

PROFESORA-FORMADORA-PESQUISADORA EN CONSTRUCCIÓN: REFLEXIONANDO SOBRE LA PRÁCTICA MEDIADA POR EJES INTEGRADORES

\section{Kelly Almeida de Oliveira (iD)}

Mestrado em Cultura e Sociedade (UFMA)

Professora na Universidade Federal do Maranhão (UFMA) Discente do Programa de PósGraduação em Educação em Ciências e Matemática (PPGECEM/REAMEC)

ka.oliveira@ufma.br

\section{Idemar Vizolli (iD) 9}

Doutorado em Educação (UFPR) Professor na Universidade Federal do Tocantins (UFT)

Docente dos Programas de Pósgraduação em Educação (UFT), em Educação em Ciências e Matemática (PPGECEM/REAMEC) e em Educação na Amazônia (EDUCANORTE) idemar@mail.uft.edu.br

\section{José Vicente de Souza Aguiar (iD) 9}

Doutorado em Educação (UFRGS) Professor na Universidade do Estado do Amazonas/campus Manaus (UEA)

Docente do Programa de Pósgraduação em Educação em Ensino de Ciências, em Educação em Ciências e Matemática (PPGECEM/REAMEC) e em Educação na Amazônia (EDUCANORTE) jvicente@uea.edu.br

\begin{abstract}
Resumo
O estágio de docência no doutorado compõe a formação continuada de professoras/es que atuam nas licenciaturas. O presente texto é motivado pela seguinte questão problematizadora: Que percursos formativos são viabilizados pelo estágio de docência para as/os doutorandas/os da Rede Amazônica de Educação em Ciências e Matemática (REAMEC)? Tem por objetivo refletir sobre o percurso formativo realizado no estágio de docência na Rede Amazônica de Educação em Ciências e Matemática (REAMEC). Trata-se de um trabalho descritivo, qualitativo e reflexivo. Os dados foram coletados por meio de observações e rodas de conversa durante as aulas, reuniões de planejamento e visita às escolas. Dentre os resultados destacamos as contribuições para o delineamento do projeto de pesquisa, considerando os conceitos incorporados, a aproximação com o objeto de estudo e a articulação com a tese. Concluímos que o estágio docência é um campo de conhecimento que congrega e articula as múltiplas experiências que fazem parte da vida e do fazer docente.
\end{abstract}

Palavras chave: Formação docente. Estágio de docência. Percurso formativo.

Recebido em: 9 de março de 2021. Aprovado em: 16 de maio de 2021.

Como citar esse artigo (ABNT):

OLIVEIRA, Kelly Almeida de; VIZOLLI, Idemar; AGUIAR, José Vicente de Souza. Docente-formadora-pesquisadora em devir: refletindo sobre o estágio mediado por eixos integradores. Revista Prática Docente, v. 6, n. 2, e030, 2021. http://doi.org/10.23926/RPD.2021.v6.n2.e030.id1039 


\section{Abstract}

Teaching internship in the doctorate is part of the continuous training of teachers who work in undergraduate courses. This text is motivated by the following problematic question: what training itineraries are possible thanks to the teaching internship for REAMEC (Amazonian Network of Education in Sciences and Mathematics) doctoral students? It aims to reflect on the formative path taken in the teaching internship at REAMEC (Amazonian Network of Education in Sciences and Mathematics). It is a descriptive, qualitative and reflective work. Data was collected through observations and conversation circles during classes, planning meetings and school visits. Among the results, we highlight the contributions to the design of the research project, considering the incorporated concepts, the approach with the object of study and the articulation with the thesis. We conclude that teaching internship is a field of knowledge that brings together and articulates the multiple experiences that are part of teachers' life and teaching practice. Keywords: Teacher training. Teaching internship. Formative path.

\section{Resumen}

La práctica docente en el doctorado es parte de la formación continua de los docentes que trabajan en cursos universitarios de formación de profesores. Este texto es motivado por la siguiente pregunta problemática: ¿qué itinerarios formativos son posibles gracias a la práctica docente para las/las doctorandas/os de REAMEC (Red Amazónica de Educación en Ciencias y Matemáticas)? Tiene como objetivo reflexionar sobre el camino formativo tomado en la práctica docente en REAMEC (Red Amazónica de Educación en Ciencias y Matemáticas). Se trata de un trabajo descriptivo, cualitativo y reflexivo Los datos se recolectaron a través de observaciones y círculos de conversación durante las clases, reuniones de planificación y visitas a escuelas. Entre los resultados, destacamos los aportes al diseño del proyecto de investigación, considerando los conceptos incorporados, la aproximación con el objeto de estudio y la articulación con la tesis. Concluimos que la práctica docente es un campo de conocimiento que aglutina y articula las múltiples experiencias que forman parte de la vida de los/las profesores/as y de la actividad docente.

Palabras clave: Formación docente. Práctica docente. Camino formativo. 


\section{INTRODUÇÃ̃o}

Cada doutoranda/o ${ }^{1}$ escolhe como viver seu estágio. Sob o olhar atento das/os orientadoras/es, ela/e decide como será seu percurso formativo. Estar aberta/o às possibilidades que se apresentam é o que determina a profundidade, a extensão e as repercussões das experiências formativas sobre a atividade docente. O estágio de docência, no processo de doutoramento é, desse modo, um componente do processo de formação continuada de professoras/es que atuam em licenciaturas, haja vista que é nelas "[...] que os futuros docentes realizam o estágio de docência como condição obrigatória para a sua formação profissional como professores" (CAVALCANTI; MARTINES, 2018, p. 30).

O estágio de docência, no âmbito da Pós-Graduação em Educação em Ciências e Matemática (PPGECEM), da Rede Amazônica de Educação em Ciências e Matemática (REAMEC), é um componente curricular obrigatório para todas/os doutorandas/os cujo objetivo é "proporcionar experiências inovadoras em ensino e aprendizagem de Ciências e Matemática, ligadas a práticas docentes no Ensino Superior e na Educação Básica” (APCN, $2008, \mathrm{~s} / \mathrm{p})^{2}$.

Em que pese a complexidade que envolve os percursos formativos vivenciados nos estágios de cursos de formação de professoras/es, a vinculação do estágio de docência às atividades acadêmico-científicas agrega novas possiblidades de realização, posto que as/os professoras/es em formação doutoral em Educação em Ensino de Ciências e Matemática “[...] precisam ser qualificados com atributos especiais de autonomia, de competência e de inovação, que os tornem capazes de formular, planejar, desenvolver e avaliar" (DARSIE, 2011, p. 365) projetos, metodologias e produtos na Amazônia.

De modo a responder a pergunta "que percursos formativos são viabilizados pelo estágio de docência para as/os doutorandas/os da Rede Amazônica de Educação em Ciências e Matemática (REAMEC)?” nosso objetivo é refletir sobre o percurso formativo realizado no estágio de docência na Rede Amazônica de Educação em Ciências e Matemática (REAMEC). Dessa forma, organizamos o percurso formativo vivenciado no estágio docência em três eixos integradores: a supervisão de estágio, a elaboração do projeto de formação continuada de professoras/es e o acompanhamento docente, que nos conduziram à sistematização das

\footnotetext{
${ }^{1}$ Optamos por utilizar os termos no feminino primeiro devido a autora do texto ser a doutoranda em questão.

${ }^{2}$ Optamos por utilizar a APCN em detrimento do Regimento Interno do Programa porque apresenta informações detalhadas do estágio docência.
} 
experiências com o estágio de docência descritas a seguir, acompanhadas de uma análise reflexiva.

\section{Procedimentos Metodológicos}

O estágio em docência também se consituiu como uma atividade de pesquisa (PIMENTA; LIMA, 2006). A investigação das normas institucionais da Rede Amazônica de Educação em Ciências e Matemática (REAMEC) para o estágio docência nos conduziu às leituras de Pimenta, Lima (2006), Spinoza (2009) e Merleau-Ponty (2003), que compuseram o referencial teórico-metodológico para nossas reflexões.

Nesse âmbito, assumimos a pesquisa qualitativa por tratar-se "[...] de um meio para explorar e para entender o significado que os indivíduos ou os grupos atribuem a um problema social ou humano" (CRESWELL, 2010, p. 26). Abarcamos as vivências e as experiências da doutoranda de modo a considerá-las como elementos de um campo de conhecimento para a docência. As atividades foram desenvolvidas no período de um ano, tendo 2019.2 e 2020.1 como os semestres de referência. No que concerne à pesquisa de campo que integra este estudo, destacamos as técnicas de observação participante, entrevistas e rodas de conversa.

Os dados foram produzidos nas reuniões de estudo e planejamento com as/os estagiárias/os do Curso de Pedagogia, da Universidade Federal do Maranhão (UFMA), campus Codó, e no momento das visitas às escolas públicas municipais, campo de estágio; durante a elaboração do projeto com as/os professoras/es da Universidade Federal do Maranhão (UFMA) - campus Codó - e da rede pública municipal de Codó - MA; e durante as aulas de Geografia da Universidade do Estado do Amazonas (UEA), campus Manaus. Os resultados foram descritos em formato dissertativo.

\section{O PERCURSO FORMATIVO}

A supervisão do estágio em ensino de ciências foi vivenciada no segundo semestre do ano de 2019, no curso de Licenciatura em Pedagogia, na Universidade Federal do Maranhão (UFMA), campus Codó. Nesse sentido, quando "[...] a disciplina que o doutorando ministra for o próprio estágio supervisionado da Licenciatura, este se constituirá em especial momento para desenvolver com os graduandos experiências na Educação Básica” (APCN, 2008, s/p). Por isso, optamos pela inclusão dessa experiência como eixo integrador.

Em junho de 2020, elaboramos um projeto intitulado Pedagogia dos cocais: diálogo entre saberes para submissão ao Edital Equidade Racial na Educação Básica: pesquisas 
aplicadas e artigos científicos, promovido pelo Centro de Estudos das Relações de Trabalho e Desigualdades (CEERT). Essa experiência compõe o percurso formativo durante o estágio de docência porque "O doutorando, sob a supervisão de seu orientador/coorientador, deverá propor um projeto de formação continuada para professores de ciências e matemática de escolas públicas" (APCN, 2008, s/p.). Esse projeto foi elaborado enquanto as atividades acadêmicas na Universidade do Estado do Amazonas (UEA), Universidade Federal do Tocantins (UFT) e Universidade Federal do Maranhão (UFMA) estavam suspensas devido à pandemia causada pelo coronavírus, denominado SARS CoV-2 (COVID-19), cujos números de mortes no país em agosto foi 28.947 e em outubro de 154.226. Diante dessa situação, as atividades correlatas ao estágio docente ocorreram de forma remota, inclusive as reuniões de orientações.

O acompanhamento docente no Curso de Licenciatura em Geografia da Universidade do Estado do Amazonas (UEA) - campus Manaus, aconteceu com o professor regente de uma disciplina pedagógica na graduação, que desempenhou a função de tutor, conforme previsto na APCN da REAMEC. De modo a refletir sobre o percurso formativo realizado no estágio de docência na Rede Amazônica de Educação em Ciências e Matemática (REAMEC), descrevemos as três experiências que compõem o percurso formativo.

\subsection{O ESTÁGIO EM ENSINO DE CIÊNCIAS}

A experiência com a supervisão de estágio no Curso de Pedagogia se articulou com a disciplina Educação em Ciência, Tecnologia e Cidadania, no Programa de Pós-graduação em Educação em Ciências e Matemática, no nível do doutorado, da Rede Amazônica de Educação em Ciências e Matemática (REAMEC). A disciplina foi ministrada de forma eletiva pelo programa, no período de 18 a 23 de setembro de 2019, em São Luís - MA. Na referida disciplina, tivemos contato com o enfoque Ciência-Tecnologia-Sociedade (CTS), alfabetização e letramento científico e questões sociocientíficas para o ensino de ciências na pósmodernidade. As conexões entre a disciplina cursada e a supervisão em Estágio em Ensino de Ciências, do Curso de Pedagogia da Universidade Federal do Maranhão (UFMA), campus Codó, tornaram-se evidentes. A proposição de práticas inovadoras voltadas para a Educação Básica, conforme consta na APCN da REAMEC, passou a ser prioridade.

O curso de Pedagogia da Universidade Federal do Maranhão (UFMA), campus Codó, em cumprimento à legislação educacional, está organizado em quatro "áreas de atuação profissional" que fazem parte do núcleo de aprofundamento e diversificação dos estudos e complementam o percurso profissional escolhido pelos estudantes a partir do sétimo semestre, 
a fim de enriquecer o currículo de formação. Assim sendo, as áreas são: Educação de jovens e adultos (EJA), Educação do Campo, Educação Inclusiva e Ensino de Ciências. Esta última está voltada para uma complementação na formação de pedagogas/os para atuarem com o ensino de ciências nos anos iniciais do Ensino Fundamental (UNIVERSIDADE FEDERAL DO MARANHÃO, 2018).

Essa área de atuação profissional é composta por três disciplinas específicas: Metodologia Científica, Práticas Educacionais Interdisciplinares no Ensino de Ciências e Didática, Currículo e Avaliação no Ensino de Ciências, além de um estágio obrigatório em ensino de ciências ${ }^{3}$, com 90 (noventa) horas de duração.

O estágio obrigatório em ensino de ciências contempla o trabalho pedagógico da área de conhecimento Ciências na Educação Infantil e nos Anos Iniciais do Ensino Fundamental. Ele visa promover aos estudantes momentos de planejamento, utilização de sequências didáticas, elaboração de projetos de trabalho, tendo em vista a alfabetização científica numa perspectiva interdisciplinar. Em sua estrutura, é possível visualizar quatro etapas: nas 10 horas iniciais estão previstas reflexões introdutórias ao estágio, organização do plano de trabalho e adequação do termo de compromisso; a segunda etapa prevê 10 horas para investigação da docência no contexto escolar; na terceira etapa, são destinadas 60 horas para construção da docência no cotidiano escolar; na última etapa, 10 horas para produção do relatório e socialização das aprendizagens por meio de evento acadêmico relativo ao estágio que congrega as/os estagiárias/os, as secretarias de educação de Codó e Timbiras, as/os supervisoras/es e as/os gestoras/es das escolas.

A supervisão docente foi desenvolvida com 10 estudantes que cursavam o sétimo período de Pedagogia e realizaram o estágio em ensino de ciências nos anos iniciais do Ensino Fundamental em três escolas públicas municipais de Codó - MA, no período matutino e vespertino. As/Os estagiárias/os tinham, como opção, realizar as atividades em duplas ou individualmente.

A ambientação das/os estagiárias/os ocorreu no início de setembro de 2019, momento em que elas/es puderam visitar três escolas da rede pública municipal, que oferecem os anos iniciais do Ensino Fundamental, solicitar autorização para realização do estágio, apresentar a proposta e coletar as assinaturas referentes à autorização para realização do estágio. Em

\footnotetext{
${ }^{3}$ O estágio no curso de Pedagogia da UFMA/campus Codó é considerado como um componente curricular e não como uma disciplina.
} 
seguida, as/os estagiárias/os realizaram as primeiras observações da escola, das/os professoras/es e das/os alunas/os, além da definição das turmas e da escolha das professoras regentes das turmas. As observações que ocorreram nesse período aconteceram de forma participativa, durante as aulas de ciências, em diferentes turmas dos anos iniciais.

A etapa destinada à regência aconteceu de outubro a novembro de 2019. Nela, as/os estagiárias/os ministraram aulas de ciências sob a supervisão técnica da professora regente da turma. Dentre outras temáticas, destacamos: as partes da planta, os tipos de solo, a água no planeta, os animais, os estados físicos da água, o ar, o cuidado com a escola e a alimentação saudável. Além de ministrar aulas, couberam às/aos estagiárias/os elaborar os planos de aula para serem avaliados e, caso necessário, readequados pelas supervisoras.

Como culminância, as/os estagiárias/os elaboraram um projeto de ensino. Elas/es tinham a autonomia para escolher um tema sociocientífico relevante tinham a autonomia para escolher um tema sóciocientífico relevante, no contexto de formação e atuação profissional, para que desenvolvessem estratégias de ensino em articulação com os conhecimentos científicos, culturais, políticos, sociais, econômicos e tecnológicos para tomada de decisões pelos sujeitos - estudantes/cidadãos envolvidos nas escolas-campo de estágio. Também possuíam autonomia para executar seus projetos de intervenção, seguindo o planejamento definido pela professora regente e pela escola. Por exemplo, uma das estagiárias relatou que, ao chegar às salas de $1^{\circ}$ e $3^{\circ}$ anos, percebia a falta de organização e papeis jogados pelo chão. Observando e conversando com as crianças, ela percebeu a necessidade de desenvolver seu projeto de intervenção voltado para o cuidado com o meio ambiente, bem como a importância de manter a escola limpa e organizada. Assim sendo, cada dupla escolheu uma temática relacionada às observações e às dificuldades encontradas em sala de aula e na escola.

O acompanhamento da elaboração do projeto de ensino pelas/os estagiárias/os foi realizado mediante reuniões de estudo e planejamento acerca do enfoque Ciência-TecnologiaSociedade (CTS). Utilizamos os textos estudados na disciplina eletiva do doutorado para orientar as/os estagiárias/os na elaboração de seus projetos.

O ensino com enfoque Ciência-Tecnologia-Sociedade (CTS) é aquele que trata da interrelação de conceitos. É uma concepção de ensino voltada para a cidadania, para promover o acesso ao conhecimento científico, mediante a tomada de decisão, tendo em vista o bem coletivo, para que as/os estudantes tenham mais uma possibilidade de ler o mundo e interagir com ele e com as pessoas. O processo tem início com uma problemática ligada a um tema 
social. Esse, por sua vez, impulsiona a exploração de conceitos científicos. Ao final do processo, uma decisão precisa ser tomada. A qualidade das decisões dependerá do acesso que tiveram ao conhecimento escolar, para poder comparar as concepções que possuem com o conhecimento científico. Convém relembrarmos os cinco passos para uma abordagem CTS, na perspectiva de Santos, Schnetzler (2010, p. 85):

\footnotetext{
1. Uma questão social é introduzida

2. Uma tecnologia relacionada ao tema social é analisada

3. O conteúdo científico é definido em relação ao tema e à tecnologia

4. A tecnologia correlata é estudada em função do conteúdo

5. A questão social é discutida.
}

Na reunião com as/os estagiárias/os do dia 26 de setembro, os textos para discussão no grupo foram apresentados. A exposição foi iniciada com o conceito de enfoque CiênciaTecnologia-Sociedade (CTS). Após as discussões, em conjunto com as supervisoras técnicas, cada dupla de estagiárias/os escolheu um tema social, uma tecnologia e um conteúdo a ser trabalhado. A tecnologia escolhida por todas as duplas foi o dicionário. As/os estagiárias/os perceberam que para cada turma havia, no máximo, dois dicionários disponíveis. Então, optamos por confeccionar os dicionários juntamente com as crianças. Assim, cada criança confeccionaria o seu próprio dicionário de ciências com imagens e objetos variados. Com vistas a torná-los acessíveis e a desenvolver consciência ambiental, os dicionários foram confeccionados com materiais recicláveis e expostos durante a Semana Municipal de Ciência e Tecnologia de Codó, que ocorreu de 11 a 14 de novembro de 2019.

As reuniões de estudo e planejamento foram acompanhadas de visitas às escolas campo de estágio. Esses foram momentos oportunos para acompanhar as/os estagiárias/os e receber o feedback das supervisoras e demais funcionários das escolas, ao se constituírem como momentos avaliativos. Os relatos e as avaliações realizados pelas supervisoras foram favoráveis ao desenvolvimento das atividades de estágio. Com o término do estágio, isso nos trouxe a compreensão de como utilizar o enfoque Ciência-TecnologiaSociedade (CTS) nas aulas de ciências e a prospecção de novos projetos pedagógicos que considerem as/os estudantes como protagonistas do conhecimento.

A supervisão de estágio de ciências no curso de Pedagogia da Universidade Federal do Maranhão (UFMA), campus Codó, possibilitou a conexão com as disciplinas cursadas no doutorado e o contato com o enfoque Ciência-Tecnologia-Sociedade (CTS) permitiu o 
desenvolvimento de novas metodologias para o ensino de ciências nos anos iniciais da Educação Básica.

\subsection{Projeto PEDAgogia dos COCAIS: diálogo ENTRE SABERES}

O projeto "Pedagogia dos Cocais: diálogo entre saberes", direcionado à formação de professoras/es dos Anos Iniciais do Ensino Fundamental ( $1^{\circ}$ ao $5^{\circ}$ ano), modalidade Educação de jovens e adultos (EJA), Linha Temática 2, Perspectivas Epistemológicas e Processos de Aprendizagem e Ensino, com Subtema: 3.2.3. Educação Escolar Quilombola, foi submetido ao edital Equidade racial na Educação Básica do Centro de Estudos das Relações de Trabalho e Desigualdades (CEERT), agência financiadora de projetos cujo objetivo é a promoção de igualdade de raça e gênero.

Os professores orientadores supervisionaram a elaboração do projeto, cujo comitê gestor foi composto pela/os autora/es deste artigo e pelo docente representante de uma escola da rede púbica municipal de Codó/MA. A equipe de trabalho foi composta por quatro docentes efetivos da Universidade Federal do Maranhão (UFMA), uma estudante de mestrado, duas graduandas em Pedagogia e um professor da escola indicada pela Secretaria Municipal de Educação de Codó. O projeto contava também com a parceria da Associação comunitária dos Trabalhadores no beneficiamento do babaçu de Codó/MA.

O projeto teve como objetivo desenvolver práticas de alfabetização e letramento na perspectiva de Freire (2001) que considerassem a articulação entre os saberes escolares e os saberes tradicionais de Quebradeiras de coco babaçu, por meio da interseccionalidade entre identidade e raça. A discussão aconteceu no campo da Educação de jovens e adultos (EJA) (ARROYO, 2011), no campo da Educação Popular e na intersecção com a Educação Escolar Quilombola (ARRUTI, 2017). A sustentação teórica do projeto constituiu, também, dos Estudos Decoloniais, em que priorizamos Quijano (2005) e Mignolo (2003); no que se refere à colonialidade do saber e das Epistemologias do Sul, na perspectiva de Santos (2009), mediado pelo método colaborativo na perspectiva de Desgagné (2007).

Uma turma da escola indicada pela Secretaria Municipal de Educação, Ciência, Tecnologia e Inovação (SEMECTI) seria o público do projeto. Dentre os saberes cartografados, teríamos três específicos: coleta, quebra do coco e produção do azeite de babaçu, pelos quais identificaríamos saberes sendo mobilizados por ocasião do processo de alfabetização. 
Posteriormente, a relação com os saberes escolares seria estabelecida, com destaque para os saberes escolares no campo da matemática e de ciências.

Como o projeto não foi selecionado entre os quinze melhores para receber o financiamento da instituição promotora do certame, ele não pode ser executado. Aguardamos uma nova oportunidade para sua implementação. Dentre as 605 submissões de projetos, fomos convidadas/os para entrevista com as membras responsáveis pela seleção. Essa atividade colaborou para a formação docente, no que diz respeito à elaboração de projetos a partir dos indicadores apresentados pela escola.

\subsection{ACOMPANHAMENTO DOCENTE}

A escolha pela disciplina de Filosofia da Educação, ministrada no curso de Geografia da Universidade do Estado do Amazonas (UEA), aconteceu de forma amistosa e consensual entre os orientadores e a doutoranda, uma vez que, em agosto de 2020, as atividades docentes ainda estavam paralisadas na Universidade Federal do Tocantins (UFT) e na Universidade Federal do Maranhão (UFMA). O estágio foi realizado no turno matutino, às quartas-feiras, das $8 \mathrm{~h}$ às $12 \mathrm{~h}$ (horário de Manaus) na turma 2020.1. Todas as aulas foram remotas, gravadas e disponibilizadas para a turma.

A carga horária total do componente curricular Filosofia da Educação foi de $60 \mathrm{~h}$. A ementa estabelecia: estudos teóricos-metodológicos relacionados aos sentidos e às tarefas da filosofia na educação; relações entre a Filosofia, a Pedagogia e as Ciências da Terra no processo de formação de professores; concepções de Filosofia da educação; autores e tendências contemporâneas da filosofia da educação no Brasil; Filosofia, educação, ética, ideologia, cultura, política; e, emancipação histórica no horizonte do sujeito e sua conduta cidadã. O objetivo era contribuir com a formação das/os professoras/es da educação básica, abordando as reflexões sobre a educação e a pedagogia, sob a perspectiva filosófica, a partir de diferentes enfoques teóricos e temáticos que versam sobre as relações entre a filosofia e a educação.

No primeiro semestre de 2020, foram matriculadas/os 63 estudantes nesse componente curricular. Desse total, apenas 47 continuaram ativas/os até o término do componente. Os demais tiveram sua matrícula cancelada. Em virtude da situação atípica provocada pela pandemia da SARS CoV-2 (COVID-19), vários estudantes relataram a preocupação com o desenvolvimento das atividades, tendo em vista os casos de adoecimento em membros de suas famílias e a desmotivação para as aulas. Atribuímos a esse fator o alto índice de desistências ao longo da disciplina. Esse momento requereu de nós empatia e 
solidariedade com as/os estudantes, considerando que esse foi o período mais crítico da doença entre as/os manauenses.

As aulas presenciais foram suspensas em março e retomadas em agosto de 2020 de forma remota. Quando retornaram, foram ministradas com uso da plataforma classroom.google.com para hospedar os textos, as mídias e as atividades, e o Google Meet foi utilizado para as exposições e análises dos textos. Foram utilizados também recursos audiovisuais (imagens, fotografias, desenhos, gráficos, esquemas), seguidas de discussões e debates entre o professor e os alunos sobre as temáticas selecionadas, de modo que eles criassem entendimentos sobre a relação entre a Filosofia, a Educação e perspectivas de Vida.

A disciplina foi organizada em quatro unidades, a saber: I - Os princípios éticos articulados ao agir na vida e na vida docente; II - Filosofia, Educação, Vida e Liberdade; III A abordagem filosófica fenomenológica e a pesquisa em geografia a considerar o mundo vivido; e, IV - O pensamento filosófico e diálogos com as ideais de pós-modernidade. A primeira unidade iniciou em 3 de março de 2020 com a apresentação do plano de estudo e introdução à Filosofia da Educação por meio da exposição oral.

A aula seguinte aconteceu após a retomada das atividades acadêmicas pela Universidade do Estado do Amazonas (UEA), de forma remota, no dia 5 de agosto. Nessa aula, problematizamos o ser ético, tendo como texto-base a entrevista "A Ética ou o fim do Mundo", realizada com o filósofo brasileiro Renato Janine Ribeiro em 2008. Em tom de diálogo, conversamos sobre como o sujeito pode e deve ser responsável por suas ações, lidando com rupturas, sem fazer pactos de ética e esperando recompensas. Dentre outros argumentos, foi utilizado o fato de que respeitar as leis por medo não significa ser ético, assim como descumprir as leis por convicções morais, assumindo as consequências, pode ser considerado ético. Esse constitui seu principal dilema (RIBEIRO, 2008).

Durante as aulas de agosto, tivemos uma continuidade da temática proporcionada pelo vídeo "A Ética necessária: responsabilidade e solidariedade”, de Franklin Leopoldo e Silva", com o objetivo de relacionar o pensar e o agir profissional com base em princípios éticos. Nessa aula, dialogamos sobre como a sociedade capitalista se transformou em uma sociedade de produção e se a liberdade é realmente um bem ou não dentro desse modelo de sociedade, uma vez que esse também é um problema ético.

\footnotetext{
${ }^{4}$ Disponível em https://www.youtube.com/watch?v=dFRMFAgBLpQ. Acesso em: 10 ago. 2020
} 
As discussões foram subsidiadas pelo Livro I - O que é o bem para o homem, de Aristóteles, nas quais problematizamos sobre a atualidade de seu pensamento, uma vez que para ele a ética está para o bem, em que há compatibilidade entre a arte (fazer bem alguma coisa) e a finalidade para o bem fazer. Para o sistema capitalista não há uma moral. Para quem visa o dinheiro, a saúde é um meio, não o fim. Do ponto de vista aristotélico, isso não é ser ético (ARISTÓTELES, 1991).

A segunda unidade iniciou com uma introdução ao pensamento do filósofo Baruch de Spinoza (1632-1677) a fim de pensar a potência dos afetos na e para a educação (NOVIKOFF; CAVALCANTI, 2015). O objetivo dessa aula foi entender a formulação filosófica da ideia de liberdade na relação entre corpos e afetos. Além de ler o texto base, o professor indicou assistir as palestras de Giacóia (2017), intitulada “O poder dos afetos em Spinoza", e de Martins (2017), intitulada "O conhecimento como o maior dos afetos"6.

Nas duas aulas, houve uma referência clara à obra "Ética", de Spinoza (2009). O filósofo racionalista holandês que viveu no século XVII influenciou o pensamento de outros filósofos contemporâneos como Foucault, Deleuze, Derrida, Nietzsche, Bergson, Guattari e Levinas. Em suas análises, o foco não está nos aspectos econômicos, eles promovem um outro tipo de crítica. O foco da discussão de Spinoza, por exemplo, está no corpo. Após uma breve exposição, nós nos concentramos na Teoria dos afetos de Spinoza.

As aulas de setembro iniciaram com a avaliação dos encontros anteriores, momento em que os discentes tiveram a oportunidade de falar sobre suas aprendizagens e seus anseios para a disciplina. Demos continuidade com o texto "Por uma concepção filosófica de educação", de Back (2019), a fim de reconhecer a importância da Filosofia para a educação e para pensar a vida em sociedade. O texto trabalhado apresenta uma discussão interessante sobre as concepções de Filosofia da Educação. O autor se dedica a dizer o que ela não é uma metateoria, mediante uma análise fenomenológica hermenêutica baseada em Heidegger e Gadamer. Em seguida, apresentamos o vídeo "Conjugando o verbo aprender", de Muzinatti (2012), e a conferência de Silva (2016) "Quem somos nós"», como estudos complementares facultativos. As discussões proporcionaram compreender que aprender é superar obstáculos para incorporar algo do mundo. O texto discutido no dia 30 de setembro foi "Ponderações

\footnotetext{
${ }^{5}$ Disponível em https://www.youtube.com/watch?v=uzewsSYJiVc\&t=228s. Acesso em: 01 set. 2020.

6 . Disponível em https://www.youtube.com/watch?v=meuiDdg_LiI. Acesso em: 01 set. 2020.

${ }^{7}$ Disponível em https://www.youtube.com/watch?v=OkNfbivm-x0. Acesso em: 08 set. 2020.

${ }^{8}$ Disponível em https://www.youtube.com/watch?v=OCZCKiEb3-o. Acesso em: 08 set. 2020.
} 
reflexivas sobre a contribuição da fenomenologia à geografia cultural”, de Correia (2006), a fim de articular a abordagem fenomenológica à pesquisa em Geografia, especialmente no campo da Geografia Cultural.

No mês de outubro adentramos às discussões sobre Fenomenologia e Hermenêutica. Trabalhamos com o texto "Modernidade/pós-modernidade: tensões e repercussões na produção de conhecimento em educação", de Gallo (2006), buscando conhecer as perspectivas de entendimento da vida e da educação a partir do pensamento sobre a pós-modernidade. Discutimos que chegamos ao mundo pelo corpo, não pelo pensamento. $\mathrm{O}$ disciplinamento dos saberes levou à ciência. A ciência clássica exige que existamos pela condição de pensar.

O último texto discutido na disciplina foi "Contribuições de Deleuze e Guattari para as pesquisas em educação", de Corazza (2012). O objetivo era entender como se constitui a ideia de crítica aos paradigmas fixos da modernidade e à existência humana. Como atividade complementar, a turma tinha que assistir a entrevista com Silvio Gallo e destacar a relação da Filosofia para Educação na perspectiva de Deleuze. Outra discussão importante se deu em torno da obra "O visível e o invisível”, de Merleau-Ponty (2003), pelo qual aquilo que é visível tem sempre aspectos invisíveis.

O dia 21 de outubro foi reservado para a entrega de atividades e o dia 28 de outubro para a avaliação final. As avaliações de rendimentos seguiram as normas da Universidade do Estado do Amazonas. As provas foram realizadas conforme as instruções contidas no Plano de Curso, hospedado no Classroom, e entregues impreterivelmente conforme as datas estabelecidas. Cada atividade valia de 0 a 2,0 pontos. Outras informações foram repassadas pelo Google Meet e em conversas pelo whatsapp com o representante discente. As fontes de pesquisas sugeridas foram os canais do youtube Café Filosófico CPFL, Hora da Coruja, Casa do Saber, Quem Somos Nós e Território Conhecimento. Como a disciplina foi desenvolvida de forma remota, essas indicações complementares foram propostas para atender o deslocamento promovido das aulas presenciais para as remotas, oriundas da crise de saúde pública vivida no Estado do Amazonas e no Brasil.

Os estudantes participaram das aulas por meio de chat ao vivo, de e-mails e contatos pelas redes sociais, dentre elas, a mais utilizada foi o whatsapp. As faltas reportadas, geralmente, aconteciam pela queda do sinal de internet. Muitos tinham que acessar as aulas por meio de dados móveis, o que acabou se tornando inviável devido a retração econômica e exclusão digital sofridas pela população do norte do país. Outros dependiam de aparelhos 
emprestados ou improvisados para o acompanhamento das aulas. Grande parte da turma manifestou desinteresse e apatia para o estudo online, além de situações de ansiedade e depressão intensificadas pelo isolamento social e pelo grande número de mortes.

Nesse sentido, o Ensino Emergencial Remoto (ERE), entendido como uma modalidade “[...] de ensino que pressupõe o distanciamento geográfico de professores e alunos e foi adotado de forma temporária nos diferentes níveis de ensino por instituições educacionais para que as atividades escolares não sejam interrompidas" (MORAES, 2020, p. 48), enfrentou grandes dificuldades para atender a demanda educacional da população.

O acompanhamento docente contemplou outras atividades, tais como a participação na Reunião do Grupo de Pesquisa Fundamentos da Educação e Ensino de Ciências; a participação no Atelier de Pesquisa no Programa de Pós-Graduação em Educação na Amazônia (EDUCANORTE); e a participação na defesa de tese da Rede Amazônica de Educação em Ciências e Matemática (REAMEC). Todas as atividades constituíram elementos integradores e socializadores do estágio. De modo especial, as aulas proporcionaram diversas aprendizagens e contribuíram para o desenvolvimento da pesquisa, uma vez que autores como Merleau-Ponty, Baruch Spinoza, Paul Ricoeur, Gilles Deleuze e Félix Guatarri serão utilizados como referências bibliográficas da tese.

\section{REFLEXÕES DE UM PERCURSO FORMATIVO EM DEVIR}

A formação docente não se desenvolve em compartimentos fechados, cujos componentes estejam desconectados da vida e das outras pessoas. Ao contrário, ela acontece mediada por teias e redes que mantêm entre si unidade, integração e significação. Por isso, esta seção destina-se a refletir sobre como os eixos integradores compuseram o percurso formativo para o devir docente-formadora-pesquisadora e como eles fomentam novas e amplas reflexões para a formação de professoras/es. As reflexões aqui apresentadas não são conclusivas ou tratam de uma conduta considerada como a melhor a ser seguida, mas representam os pontos de ancoragem dos eixos formativos em que as redes e teias do percurso formativo foram tecidas.

Ao integrarmos a supervisão do estágio em ensino de ciências com a disciplina eletiva, percebemos que a supervisão de estágio na graduação representou uma espécie de laboratório de ensino para o doutorado. Como o curso de Pedagogia forma professoras/es para atuarem nos anos iniciais da escolarização, sentimos a necessidade de reformulação das metodologias para o ensino de ciências levando em consideração a alfabetização científica. 
Assumir uma nova perspectiva de ensino, como o enfoque Ciência-TecnologiaSociedade (CTS), faz com que as/os professoras/es saiam de sua zona de conforto. A tomada de decisão é o objetivo fundamental nos projetos de ensino elaborados a partir do enfoque Ciência-Tecnologia-Sociedade (CTS) (SANTOS; SCHNETZLER, 2010). Ela representa a oportunidade de buscar significação para o ensino de Ciências, pois promove a integração de conhecimentos com objetivo de formar para a cidadania, para que as/os estudantes tenham mais possibilidades de ler o mundo e interagir com ele.

A educação é uma experiência universal com vista a produção de saberes. Por isso, é importante considerar as marcas que o conhecimento deixa nas pessoas. Conceber filosoficamente algo é vê-lo sob uma perspectiva teórica conceitual. Para pensar o ser das coisas, é preciso fazer uma opção por uma abordagem científica para analisá-la, isso significa delimitar um campo epistêmico. Em face disso, emerge a ideia de experiência (GADAMER, 2003), em que a educação é basicamente a experiência em virtude da qual a consciência passa por intermináveis formações. Por isso, a formação docente, nessa perspectiva, só pode nos conceder um devir.

O que se forma na experiência é o ser mesmo de quem experimenta. Nessa medida, “educar(-se) consiste em transformar(-se)” (BACK, 2019, p. 13). A educação é uma experiência em que singularidades se afirmam. Se ela não é transformadora, é reprodutora. Sem o sujeito não há aprendizagem. Ser sujeito é decidir. É optar por um caminho. É preciso querer aprender, é necessário ser um sujeito que tem o desejo de conhecer, além das condições materiais de existência. Todavia, conhecimento não é compulsório. Conhecimento precisa ser algo que se gosta. É necessário que o corpo sofra afecções que aumentem sua potência, seu conatus, como diz Spinoza (2009).

Desse modo, elaborar um projeto de formação de professoras/es durante a pandemia de 2020 representou mais uma experiência significativa durante o percurso formativo. Empatia e solidariedade foram fundamentais para conversar com professoras/es que atuam no Ensino Superior e na Educação Básica. Conhecer as necessidades e estabelecer vínculos com as escolas da rede municipal e as demais instituições para composição de um projeto comum tornou-se um compromisso profissional e de vida. Isso faz lembrar que "se queremos praticar os valores, acreditar neles é um bom começo. Mas acreditar neles depende de uma coisa, inclusive de uma disposição dos afetos” (RIBEIRO, 2008, p. 168). A superação do individualismo radical voltado para a celebração de si próprio prescinde, dentre outras, da formação de professoras/es 
para serem éticas/os, a fim de termos uma sociedade melhor para todas as pessoas que vivem nela. Nesse sentido, a formação de professoras/es precisa se pautar pela ética, para resistir às forças capitalistas que querem reduzir a educação ao status de mercadoria, ou transformar o saber numa dimensão com valor de troca.

A ética do agir humano se dá na ação ou na omissão. A ética necessária requer responsabilidade e solidariedade consigo mesmo e com o outro. Quando a/o outra/o se torna objeto de conhecimento, ela/e é objetivada/o. E quando isso acontece, ela/e deixa de existir porque passamos a dizer como deve ser existência numa perspectiva de correção constante da sua forma de ser, de pensar e de existir. Como educadoras/es precisamos ter cuidado para não objetificar a/o outra/o, principalmente nas escolas, onde isso acontece com frequência. Assim como rever as maneiras de estar com a/o outra/o estabelecendo com ela/e um diálogo, é necessário pensar a formação de professoras/es para além de metodologias que objetificam.

Dentre as aprendizagens do acompanhamento docente, podemos destacar as contribuições de Spinoza e Merleau-Ponty ao entendimento de que o relacionamento interpessoal é uma dinâmica de afetos. Na tensão entre os corpos, em que um quer subjugar o outro, precisamos criar a sensibilidade para entender que a vida é muito mais que domínios de conhecimentos com usos utilitários.

Em Spinoza (2009), afeto está para a ação de afetar. Os afetos agem sobre o corpo e a mente. A essência é a força do corpo para continuar sua existência. Essa força torna o corpo potente ou não. As três afecções básicas são: conatus (desejo), alegria e tristeza. Os afetos alegres aumentam o conatus. Os afetos tristes o diminuem. Assim, a alegria é a potência que nos torna livres enquanto a tristeza é a potência que nos escraviza. A alegria é um afeto ativo enquanto a tristeza é um afeto passivo. Desse modo, é essencial que haja dois corpos para que ocorra afecção de um sobre o outro, sobretudo as afecções que aumentam nosso conatus para vida livre.

À semelhança de Merleau-Ponty (2003), Spinoza trabalha com o mundo da imanência, com o mundo vivido, com a facticidade, com o mundo da experiência, com o mundo real onde os afetos são dinâmicos. Decorre disso a epistemologia contida em seu pensamento. Ele apresenta três gêneros do conhecimento que coexistem no mesmo ser: (i) imaginação - o corpo é guiado pelas fantasias, pelas ilusões (representa o primeiro contato com o mundo); (ii) razão - refere-se à capacidade de conhecer as causas, a ordem das relações, mas que se restringe à reprodução; e, (iii) intuição intelectual - refere-se ao gênero do risco, da transgressão, em que 
se passa do conhecimento dos graus de potência para a inventividade e criatividade ou seja, usa a razão e a imaginação. Desse modo, o agir, segundo o terceiro gênero espinoziano, é pensar e agir por si próprio a partir do conhecimento mediado pela razão (SPINOZA, 2009).

Os afetos são potências em variação. A vida acontece pelo encontro de corpos fortes e corpos fracos. Aumentar a potência de uma pessoa é expandir seu território de ação. É preciso expandir a potência positiva para que o aprendizado seja livre e ativo. O prazer e o gosto de conhecer algo, portanto, aumentam o conatus.

Durante o acompanhamento docente, uma interrogação se tornou crucial: como a sala de aula se torna um lócus de encontros bons, alegres e ativos? Estudar não começa na mente, começa na pele (união mente e corpo). A longa tradição da educação escolar priorizou o cognitivo. O mesmo fez Descartes. Estudar é enamorar-se. É necessário um encontro com alguma coisa que seja significativo. A educação prescritiva e normativa é despotencializadora. Como esse corpo afeta e é afetado? É um corpo do controle, da disciplina, da servidão, da obediência e da submissão? Vida com medo é vida sem potência de agir em que o corpo não produz. Servidão, nesse sentido, seria a impotência humana em moderar a capacidade de afetar e ser afetado (NOVIKOFF; CAVALCANTI, 2015).

Em termos educacionais, percebemos que estamos produzindo corpos submissos em nossas escolas, em nossas aulas. É um corpo que existe, mas despotencializado devido a sucessivos processos de disciplinamento dos quais somos cúmplices quando permanecemos fixos no segundo gênero do conhecimento spinoziano. Um bom encontro com o conhecimento é o caminho para que os estudantes sejam afetados ao máximo por paixões alegres, pois ser sujeito é ser capaz de unir-se pelo amor, procurar encontros que aumentem sua potência de existir e evitar os maus encontros. É preciso, pois, alcançar o terceiro gênero do conhecimento para aumentar a potência de existir.

\section{Algumas CONSIDERAÇÕES}

Cada experiência proporciona aprendizagens. Cada aprendizagem repercute nas práticas docentes. Assim, cada estágio possui singularidades. As singularidades, uma vez consideradas como componentes do percurso formativo durante o período de estágio, possibilitam a emergência de práticas reflexivas e inovadoras.

Múltiplas atividades foram desenvolvidas ao longo do estágio de docência da Rede Amazônica de Educação em Ciências e Matemática (REAMEC) e que não se restringiram ao acompanhamento, planejamento e regência de uma disciplina ou aos limites da sala de aula. 
Isso é importante porque ele "[...] não pode ser reduzido à prática da docência, entendida essa de forma reducionista como o ato de ministrar aula" (CAVALCANTI; MARTINES, 2018, p. 37).

O estágio não pode dicotomizar teoria e prática na formação de professoras/es. Ele não é o momento prático da aplicação de uma teoria. Encará-lo dessa forma trouxe inúmeros benefícios, por exemplo, compor o estágio de docência por eixos que se articularam de forma integrada nos possibilitou desvelar nosso percurso formativo durante o curso de doutoramento. Assim, percebemos um intercâmbio intenso e diversas conexões entre o estágio de docência na pós-graduação stricto senso e o estágio de docência na graduação; entre a formação continuada e a formação inicial de professores/as; entre o curso de Ciências e Matemática e o curso de Pedagogia. Essas conexões produziram, nos conceitos spinozianos, encontros alegres.

Em relação ao projeto de formação de professoras/es, entendemos que os saberes tradicionais de Quebradeiras de coco são elementos epistemológicos que podem ser utilizados no engendramento de práticas de alfabetização e letramento, para promover a equidade racial na Educação Básica. Fomos aprovadas na primeira etapa da seleção, com a entrevista realizada no dia 23 de setembro pelas professoras do Centro de Estudos das Relações de Trabalho e Desigualdades (CEERT). Embora não tenha sido selecionado entre os quinze melhores do país, trouxe-nos imensa alegria saber que o projeto foi finalista desse certame com 605 submissões.

O contato com os autores mencionados contribuiu com um novo olhar para a disciplina Filosofia da Educação, para a docência, para a formação de professoras/es e para a escrita da tese. Durante o acompanhamento das aulas remotas, os desafios foram imensos. A falta de contato físico com a turma e a interação durante as aulas virtuais ficaram substancialmente prejudicadas. O manuseio das novas Tecnologias Digitais de Informação e Comunicação (TDIC) e os longos períodos à frente da tela do computador provocaram uma nova disposição corporal diante da dinâmica das aulas. Isso demandou maior engajamento com o estágio.

A participação em grupos de pesquisa, defesa de tese, aulas em outro programa de doutorado, supervisão do estágio, regência das aulas e a elaboração de um projeto de formação de professoras/es da Educação Básica compuseram os três eixos integradores do estágio de docência. Para as/os doutorandas/os que já são professoras/es em exercício do magistério superior, é igualmente significativo e produtivo que o estágio de docência esteja vinculado a atividades acadêmicas que possibilitem e desafiem a/o doutoranda/o a se envolver com a vida 
acadêmica mais ampla, para além da sala de aula (CAVALCANTI; MARTINES, 2018, p. 40). Dentre as possibilidades para o estágio de docência oferecidas pela Rede Amazônica de Educação em Ciências e Matemática (REAMEC), apresentamos o percurso formativo escolhido e sua composição pelos três eixos integradores na Figura 1.

Figura 1 - Percurso formativo do estágio de docência Rede Amazônica de Educação em Ciências e Matemática (REAMEC)

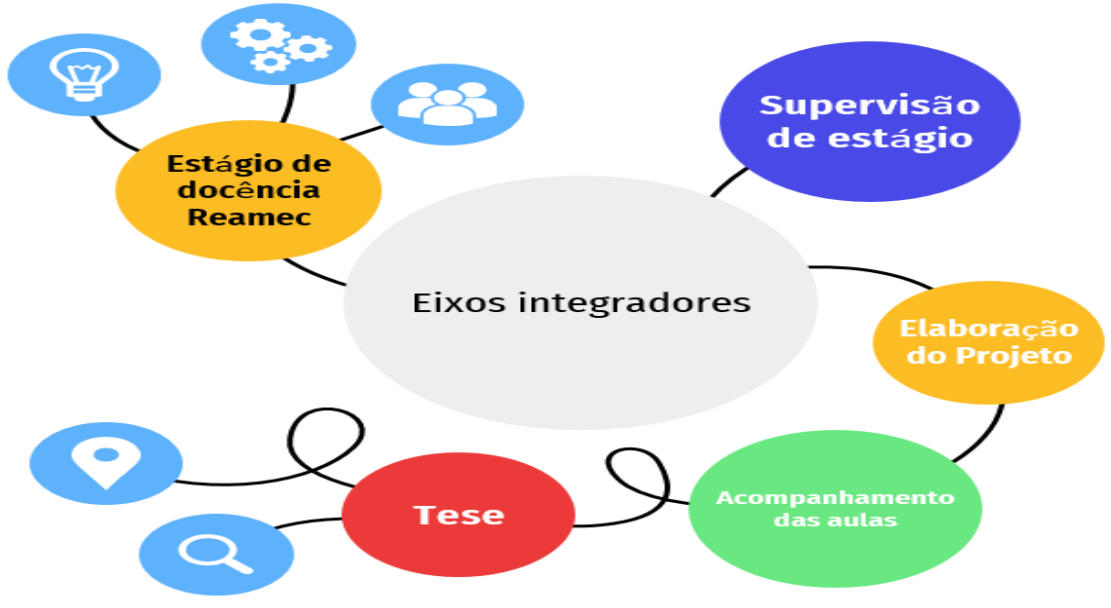

Fonte: Elaborado por Oliveira (2021).

Todo percurso formativo é dinâmico, possui pausas, recomeços e, num dado momento, muda de direção. Em se tratando da formação de professoras/es, não podemos desejar que seja retilíneo, exato e cartesiano. É preciso considerar as curvas do caminho. Desse modo, consideramos o estágio de docência da Rede Amazônica de Educação em Ciências e Matemática (REAMEC) não como uma reta de sentido único, de onde se sai de um lugar em direção a outro, mas como um campo de conhecimento que possui um estatuto epistemológico “[...] que supera sua tradicional redução à atividade prática instrumental", pela qual a constante interação que promove entre as diversas atividades acadêmicas e científicas poderá “[...] se constituir em atividade de pesquisa” (PIMENTA; LIMA, 2006, p. 6). Um campo de conhecimento que congrega e articula as múltiplas, as diversas, as complexas e as incompletas experiências que fazem parte da vida e do fazer docente.

Dentre os resultados alcançados, de modo geral, podemos observar que integrar a supervisão do estágio supervisionado, elaborar um projeto de formação continuada de professoras/es da Educação Básica e acompanhar as aulas de um dos orientadores na licenciatura constituem possibilidades para percursos formativos na Rede Amazônica de Educação em Ciências e Matemática (REAMEC), sobretudo para a/o doutoranda/o que ingressa 
no Programa tendo a formação inicial em Pedagogia. De modo particular e enquanto docenteformadora-pesquisadora, podemos dizer que o percurso formativo viabilizado pelo estágio de docência se deu a partir de três eixos integradores que contribuíram de forma salutar para o delineamento do projeto de pesquisa de doutorado, para a aproximação ao objeto de estudo e para um novo modo de ver e conceber a docência em licenciaturas, além da articulação com os fundamentos filosóficos da pesquisa em desenvolvimento.

Desse modo, consideramos essas contribuições como pontos positivos. Para nós, o principal ponto negativo foi e é a pandemia causada pelo SARS CoV-2 (COVID-19) que vitimou, no momento de finalização desse artigo, 249.957 pessoas no Brasil e 2.497.406 pessoas no mundo. Esse, em termos spinozianos, constitui um mau encontro entre o SARS CoV-2 e a humanidade.

\section{REFERÊNCIAS}

APCN apresentado à CAPES para a criação do PPGECEM / REAMEC. Cuiabá, 2008. CAPES - Coordenação de Aperfeiçoamento de Pessoal de Nível Superior. Portaria $n^{\circ} 76$, de 14 de abril de 2010. Regulamenta o Programa de Demanda Social dos programas de pósgraduação do país. Brasília, 2010.

ARISTÓTELES. Ética a Nicômaco. 4ª . ed. São Paulo: Nova Cultural, 1991. — (Os pensadores; v. 2).

ARROYO, Miguel. Educação de jovens-adultos: um campo de direitos e de responsabilidade pública. In. SOARES, Leôncio. GIOVANETTI, Maria Amélia. GOMES, Nilma Lino.

(Orgs.). Diálogos na Educação de Jovens e adultos. 4ª ed. Belo Horizonte: Autêntica, 2011.

ARRUTI, José Maurício Andion. Conceitos, normas e números: uma introdução à Educação Escolar Quilombola. Revista Contemporânea de Educação, vol. 12, n. 23, p. 107-142, jan/abr de 2017. https://doi.org/10.20500/rce.v12i23.3454

BACK, Rainri. Por uma concepção filosófica da educação. Educ. Pesqui., v. 45, p. 1-15, 2019. http://dx.doi.org/10.1590/s1678-4634201945205293

CAVALCANTI, Alberes. MARTINES, Elizabeth Antonia Leonel de Moraes. A formação doutoral em educação: repensando o estágio de docência para professores e professoras experientes. Revista REAMEC, v. 6, n. 1, p. 28-42, 2018.

http://10.26571/REAMEC.a2018.v6.n1.p28-42.15877 
CORAZZA, Sandra Mara. Contribuições de Deleuze e Guattari para as pesquisas em educação. Revista Digital do LAV, ano V, n. 08, p. 1-19, mar de 2012. https://doi.org/10.5902/198373485298

CORREIA, Marcos Antonio. Ponderações reflexivas sobre a contribuição da fenomenologia à geografia cultural. R. RA'E GA, n. 11, p. 67-75, 2006. Disponível em https://revistas.ufpr.br/raega/article/view/7749. Acesso em: 22 set. 2020.

CRESWELL, John. Projeto de pesquisa: métodos qualitativo, quantitativo e misto. $3^{\text {a }}$. ed. Porto Alegre: Artmed, 2010.

DARSIE, Marta Maria Pontin. Programa de Pós-Graduação - Doutorado em Educação em Ciências e Matemática - PPGECEM - da Rede Amazônica de Educação em Ciências e Matemática - REAMEC. Revista de Educação Pública, v. 20, n. 43, p. 357- 377, maio/ago. 2011. Disponível em: http://periodicoscientificos.ufmt.br/ojs/index.php/educacaopublica/article/view/310/278. Acesso em: 01 dez. 2020.

DESGAGNÉ, Serge. O conceito de pesquisa colaborativa: a ideia de uma aproximação entre pesquisadores universitários e professores práticos. Revista Educação em Questão, Natal, v. 29, n. 15, p. 7-35, maio/ago. 2007. Disponível em:

https://periodicos.ufrn.br/educacaoemquestao/article/view/4443. Acesso em: $01 \mathrm{dez} .2020$.

FREIRE, Paulo. Conscientização: teoria e prática da libertação - uma introdução ao pensamento de Paulo Freire. São Paulo: Centauro, 2001.

GADAMER, Hans-Georg. Verdade e método I: traços fundamentais de uma hermenêutica filosófica. 5ª . ed. Petrópolis: Vozes; Bragança Paulista: Universitária São Francisco, 2003.

GALLO, Sílvio. Modernidade/pósmodernidade: tensões e repercussões na produção de conhecimento em educação. Educação e Pesquisa, São Paulo, v.32, n.3, p. 551-565, set./dez. 2006. https://doi.org/10.1590/S1517-97022006000300009

GIACOIA, Oswaldo. O poder dos afetos em Spinoza. Amaury Pacheco. Youtube, 2017. Disponível em https://www.youtube.com/watch?v=uzewsSYJiVc\&t=228s. Acesso em: 01 set. 2020.

MARTINS, André. O conhecimento como o maior dos afetos. Café Filosófico CPFL. Youtube, 2017. Disponível em https://www.youtube.com/watch?v=meuiDdg LiI. Acesso em: 01 set. 2020.

MERLEAU-PONY, Maurice. O visível e o invisível. $4^{\text {a }}$. ed. São Paulo: Editora Perspectiva, 2003.

MIGNOLO, Walter. Histórias locais/projetos globais: colonialidade, saberes subalternos e pensamento liminar. Belo Horizonte: Editora UFMG, 2003.

MORAES, Luana Celina Lemos de. Normas aplicáveis ao ensino remoto: uma análise das Portarias no 343 e 345 do Ministério da Educação à luz do direito brasileiro. In: PAIVA 
JÚNIOR, Francisco Pessoa de (Org.). Ensino Remoto em debate. Belém: RFB Editora, 2020, p. 45-56. https://doi.org/10.46898/rfb.9786558890607

MUZINATTI, João Luis. Conjugando o verbo aprender. Café Filosófico CPFL. Youtube, 2012. Disponível em https://www.youtube.com/watch?v=OkNfbivm-x0. Acesso em: 08 set. 2020.

NOVIKOFF, Cristina. CAVALCANTI, Marcus Alexandre de Pádua. Pensar a potência dos afetos na e para a educação. Conjectura: Filos. Educ., Caxias do Sul, v. 20, n. 2, p. 88-107, set./dez. 2015. Disponível em:

http://www.ucs.br/etc/revistas/index.php/conjectura/article/view/3442. Acesso em: 15 de agosto de 2020.

PIMENTA, Selma Garrido; LIMA, Maria Socorro Lucena. Estágio e docência: diferentes concepções. Revista Poíesis Pedagógica, PPGEDUC, Universidade Federal de Goiás, Vol. 3, No. 3 e 4, p.5-24, 2006. https://doi.org/10.5216/rpp.v3i3e4.10542

QUIJANO, Anibal. Colonialidade do poder, eurocentrismo e América Latina. In: LANDER, Edgardo (Org.). A colonialidade do saber: eurocentrismo e ciências sociais. Perspectivas latino-americana. Buenos Aires: Clacso: 2005. p. 227-278.

RIBEIRO, Renato Janine. A Ética ou o fim do Mundo. Organicom. Ano 5. n. 8, p. 161-169, 2008. https://doi.org/10.11606/issn.2238-2593.organicom.2008.138975

SANTOS, Boaventura de Sousa. Para além do pensamento abissal: das linhas globais a uma ecologia de saberes". In: SANTOS, Boaventura de Sousa; MENEZES, Maria Paula (Orgs.).

Epistemologias do Sul. Coimbra: Edições Almedina: 2009. p. 23 -72.

SANTOS, Wilson Luiz Pereira dos. SCHNETZLER, Roseli Pacheco. Educação em Química: compromisso com a cidadania. Porto Alegre: UNIJUI, 4ª ed., 2010.

SILVA, Franklin Leopoldo e. A Ética necessária: responsabilidade e solidariedade. Café Filosófico CPFL. Youtube, 2018. Disponível em: https://www.youtube.com/watch?v=dFRMFAgBLpQ. Acesso em: 10 ago. 2020.

SILVA, Franklin Leopoldo e. Quem somos nós. Casa do saber: Quem somos nós. Youtube, 2016. Disponível em https://www.youtube.com/watch?v=dFRMFAgBLpQ. Acesso em: 08 set. 2020.

SPINOZA, Benedictus de. Ética. Belo Horizonte: Autêntica, 2009.

UNIVERSIDADE FEDERAL DO MARANHÃO. Projeto Pedagógico do Curso de Pedagogia. Codó, 2018. 